\title{
Lección MOODLE de Anatomía e Histología de la Placenta Humana
}

\author{
MOODLE Lesson of the Anatomy and Histology of the Human Placenta
}

Godoy-GuzmÁn, C. ${ }^{1,2}$; Osses, M. ${ }^{1}$; San MartÍn, S. ${ }^{3}$, Leiva, G. ${ }^{4,5}$ \& Jara-Rosales, S. ${ }^{6}$

GODOY-GUZMÁN, C; OSSES, M; SAN MARTÍN, S; LEIVA, G. \& JARA-ROSALES, S. Lección MOODLE de anatomía e histología de la placenta humana. Int. J. Morphol., 37(1):178-183, 2019.

RESUMEN: La falta de muestras biológicas humanas existentes, debido principalmente a las limitaciones ético-morales relacionadas con su obtención, ponen en relieve la necesidad de buscar otras alternativas de enseñanza y aprendizaje de las ciencias morfológicas. En este sentido, la implementación de lecciones a través de la plataforma MOODLE proporciona la oportunidad al estudiante de interactuar en un entorno que simula una situación de aprendizaje propio del laboratorio tradicional. El objetivo del presente trabajo fue generar una lección MOODLE sobre la anatomía e histología placentaria humana, como complemento a la clase teórica presencial, para estudiantes de la carrera de Obstetricia y Puericultura. Para tal cometido, se realizó búsqueda de información, imágenes y recursos TIC en bibliotecas e internet. Paralelamente, se llevó a cabo un proceso de captura fotográfica de muestras histológicas de placenta, así como también la grabación de un alumbramiento. Posteriormente, se procedió a la articulación y montaje de las actividades en la plataforma MOODLE con un enfoque constructivista. Además, se elaboró una encuesta de satisfacción, la cual fue validada por 3 expertos. La muestra estuvo constituida por 137 estudiantes de la carrera de Obstetricia. Se confeccionó un laboratorio virtual MOODLE de anatomía e histología de la placenta humana, el cual esta constituido por múltiples actividades con orientación clínica, las cuales permiten autoevaluarse. El laboratorio virtual nos ha ayudado ha subsanar la carencia de muestras humanas y los resultados de la encuesta de satisfacción aplicada a los estudiantes señalan una valoración positiva de la iniciativa.

PALABRAS CLAVE: MOODLE; Placenta humana; Histología; Anatomía.

\section{INTRODUCCIÓN}

Las generaciones nacidas y educadas en un contexto altamente tecnológico, llamados "nativos digitales", acostumbrados desde niños a relacionarse con computadoras, tablet y teléfonos móviles entre otros dispositivos, ven como natural y cotidiana esta realidad (Merino Malillos, 2010). Desde un punto de vista pedagógico esto no debería representar un problema, sino una ventaja. En este contexto, la literatura ha señalado que la aplicación de este recurso a la educación, se traduciría en un aumento de la motivación de los estudiantes permitiendo una mejor integración de contenidos (Blanco, 2013).

Subramanian \& Perumal (2016) desarrollaron un conjunto de actividades en plataforma Modular Object-Oriented Dynamic Learning Environment (MOODLE) para subsanar la brecha temporal que significa tener las asignaturas de ciencias básicas en primer año y las prácticas clínicas en los últimos semestres de la carrera de fisioterapia. Los autores señalan que el $79 \%$ de los alumnos consideraron útil el recurso y un $72 \%$ manifestó comprender de manera más fácil conceptos clínicos en comparación a semestres anteriores. En esta misma línea, Popovic et al. (2018), aplicaron un modelo de aprendizaje mixto (clases presenciales y plataforma virtual) a un curso de fisiología en la Escuela de Medicina de la Universidad de Montenegro (Montenegro). Los resultados de la encuesta señalan que un $65 \%$ de los estudiantes consideró MOODLE como un complemento a los métodos tradicionales, 59,3\% que mejoró la gestión del tiempo, $90 \%$ que fue de fácil uso y un $68 \%$ recomendó la aplicación de la plataforma en otras asignaturas del plan de estudios. Dentro de las experiencias existentes de uso de TIC en las ciencias morfológicas destaca el trabajo de Prieto et al. (2011), quienes confeccionaron un blog de libre acceso con el fin de exponer material educativo sobre placenta comparada. Los autores exponen que esta modalidad fue positivamente valorada por los usuarios que visitaron el blog, un 80,6 \% manifestó que cumplía con las expectativas del visitante, a un $62 \%$ le pareció atractivo y

\footnotetext{
${ }^{1}$ Unidad de Histología, Escuela de Medicina, Universidad de Santiago de Chile, (USACH), Santiago, Chile.

${ }^{2}$ Centro de Investigación Biomédica y Aplicada (CIBAP), Escuela de Medicina, Universidad de Santiago de Chile, (USACH), Santiago, Chile.

${ }^{3}$ Centro de Investigaciones Biomédicas, Universidad de Valparaíso, Valparaíso, Chile.

${ }^{4}$ Centro de Diagnóstico Perinatal (CEDIP), Hospital de La Florida, Santiago, Chile.

${ }^{5}$ Escuela de Medicina, Pontificia Universidad Católica de Chile, Santiago, Chile.

${ }^{6}$ Escuela de Obstetricia, Facultad de Medicina y Ciencia, Universidad San Sebastián, Lota 2465, Providencia, Santiago, 7510157, Chile.
} 
en un 59,2\% le pareció novedoso, explicativo y de fácil comprensión los aspectos microscópicos disponibles en la herramienta didáctica utilizada. Por otro lado, Granero-Gallegos \& Baena-Extremera (2015) desarrollaron un estudio caso-control en la asignatura de educación física para alumnos de secundaria, donde a ambos grupos se les impartió una clase con métodos tradicionales y sólo el grupo experimental fue apoyado con actividades en la plataforma MOODLE. Finalmente, aplicaron un cuestionario sobre los contenidos estudiados, obteniendo mejor puntuación el grupo experimental apoyado por la plataforma virtual que el grupo control. En Chile, Bucarey et al. (2011) utilizaron la plataforma MOODLE para entregar contenidos sobre anatomía del hígado humano a estudiantes de Medicina, Obstetricia y Enfermería de la Universidad Austral de Chile. Luego de terminada la intervención aplicaron una encuesta de satisfacción obteniendo como resultados que un $67 \%$ de los alumnos estuvo "muy de acuerdo" con que volverían a usar esta modalidad, igual calificación recibió el indicador de que las actividades permiten alcanzar los objetivos planteados y que facilita el aprendizaje colaborativo con sus compañeros de clases.

La plataforma MOODLE o entorno modular de aprendizaje dinámico orientado a objetos, fue desarrollado por el profesor australiano Martin Dougiamas en el año 2002 (Dougiamas \& Taylor, 2002). Esta herramienta está basada en el modelo socioconstructivista que tiene por objetivo facilitar el aprendizaje colectivo, priorizando la construcción del conocimiento (Dougiamas \& Taylor, 2003). El objetivo del presente trabajo fue generar una lección MOODLE sobre la anatomía e histología placentaria humana, como complemento a la clase teórica presencial, para estudiantes de la carrera de Obstetricia y Puericultura.

\section{MATERIAL Y MÉTODO}

Grabación de video de alumbramiento y análisis macroscópico. Se grabó un video de un alumbramiento en el Servicio de Ginecología y Obstetricia del Hospital San José, Santiago, Chile. Las usuarias participantes del proyecto manifestaron su voluntad de colaborar a través de la firma de un consentimiento informado. Después del alumbramiento, se procedió al examen macroscópico de la placenta de término y un proceso de captura fotográfica de la cara fetal, materna y cordón umbilical.

Evaluación histológica. Las muestras de placenta fueron fijadas en formalina al $10 \%$, deshidratadas, aclaradas, embebidas en parafina, y seccionadas a 5 micras de grosor de acuerdo a protocolos previamente descritos (Godoy-Guzmán et al., 2012). El análisis histológico general fue realizado mediante la técni- ca de hematoxilina eosina. Las muestras fueron fotografiadas mediante un microscopio Olympus BX50 y las fotografías seleccionadas en base a un criterio didáctico y formativo.

Confección y montaje de lección MOODLE y elaboración de caso clínico. En primera instancia, se realizó búsqueda de información sobre anatomía e histología de la placenta humana (PubMed), imágenes y recursos TIC en bibliotecas e internet. Posteriormente, se efectuó el montaje de las actividades en plataforma MOODLE 2.7 con un enfoque constructivista. En esta línea, se obtuvo como resultado una lección MOODLE sobre anatomía e histología de la placenta humana, la cual tiene por objetivos; 1.-Describir la anatomía de la cara fetal y materna de la placenta de término; 2.- Describir las funciones generales de la placenta; 3.- Describir los componentes de la barrera placentaria del primer y tercer trimestre de la gestación a partir de fotomicrografías; 4.- Reflexionar en torno a un caso clínico (estudio de caso) la importancia del examen macroscópico de la placenta durante el alumbramiento.

La lección MOODLE estuvo compuesta por contenidos teóricos que abordan aspectos macroscópicos (Fig. 1) y microscópicos generales (Fig. 2) de la placenta. También, existen preguntas de selección múltiple y links a otras páginas web.

Al final de la lección se expone un caso clínico ficticio basado en un video de un alumbramiento patológico y 5 preguntas de desarrollo (Fig. 3). El estudio de caso fue elaborado por 2 expertos de acuerdo a recomendaciones descritas en la literatura y corresponde a un eje integrador de los contenidos anteriormente expuestos en la lección (Roselli, 2001; Chaparro Gómez, 2004).

Muestra y encuesta de satisfacción. En este proyecto participaron 137 estudiantes de segundo año (tercer semestre) cursando la asignatura de Histología de la carrera de Obstetricia y Puericultura de la Universidad de Santiago de Chile. La asignatura de Histología se divide en una sección teórica constituida por clases expositivas presenciales y otra parte práctica, cuyo objetivo es la identificación de estructuras de diversos tejidos biológicos a través del microscopio. La lección MOODLE está planteada como parte del trabajo autónomo y está integrada con una clase teórica expositiva titulada "Formación de placenta y anexos".

Finalmente, se elaboró una encuesta de satisfacción, la cual fue validada por Fraser et al. (1995). En dicha encuesta se evaluaron cuatro dimensiones: integración de la lección MOODLE con las clases expositivas, formato y estructura de la lección, aporte al proceso de enseñanza y aprendizaje y normas que orientan la conducta en las lecciones (Tabla I). Finalmente, la encuesta fue montada en la plataforma MOODLE. 

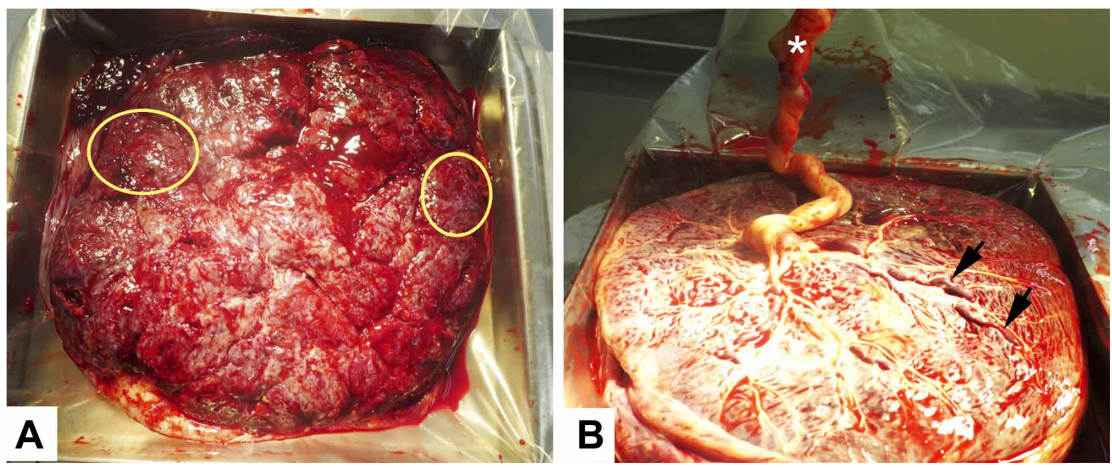

Fig. 1. Imágenes macroscópicas de la placenta humana de término disponibles en la herramienta didáctica. En la imagen A se observa la cara materna de la placenta, nótese 15 a 20 áreas ligeramente abultadas denominadas cotiledones (elipses). La imagen B corresponde a la superficie fetal, observe el cordón umbilical (asterisco) y los vasos coriónicos (flechas).
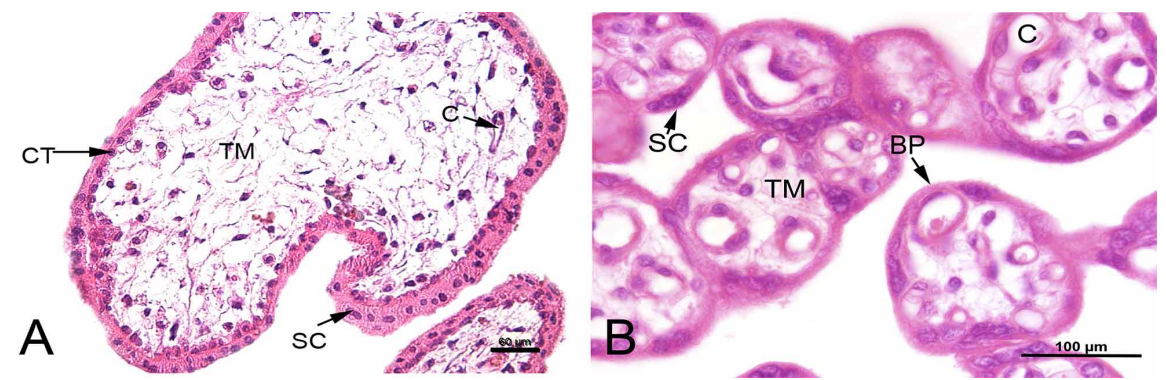

Fig. 2. Imágenes de vellosidades placentarias humanas teñidas con hematoxilina y eosina disponibles en la herramienta didáctica. En la figura A observe una vellosidad placentaria del primer trimestre de la gestación, nótese el sinciciotrofoblasto (SC) el cual corresponde a una masa multinucleada de células, sin límites celulares aparentes. Por otro lado, subyacente al SC, se observa el citotrofoblasto (CT) como una monocapa de células cúbicas. El centro de la vellosidad está compuesto por abundante tejido conectivo laxo denominado tejido mesénquimatico (TM). En la imagen B se observan vellosidades del tercer trimestre de la gestación, observe lo delgado de la barrera placentaria (BP) y su estrecha cercanía con capilares sanguíneos (C) que contienen en su interior sangre de origen embrionaria o fetal. Además, se observa escaso tejido mesenquimático.
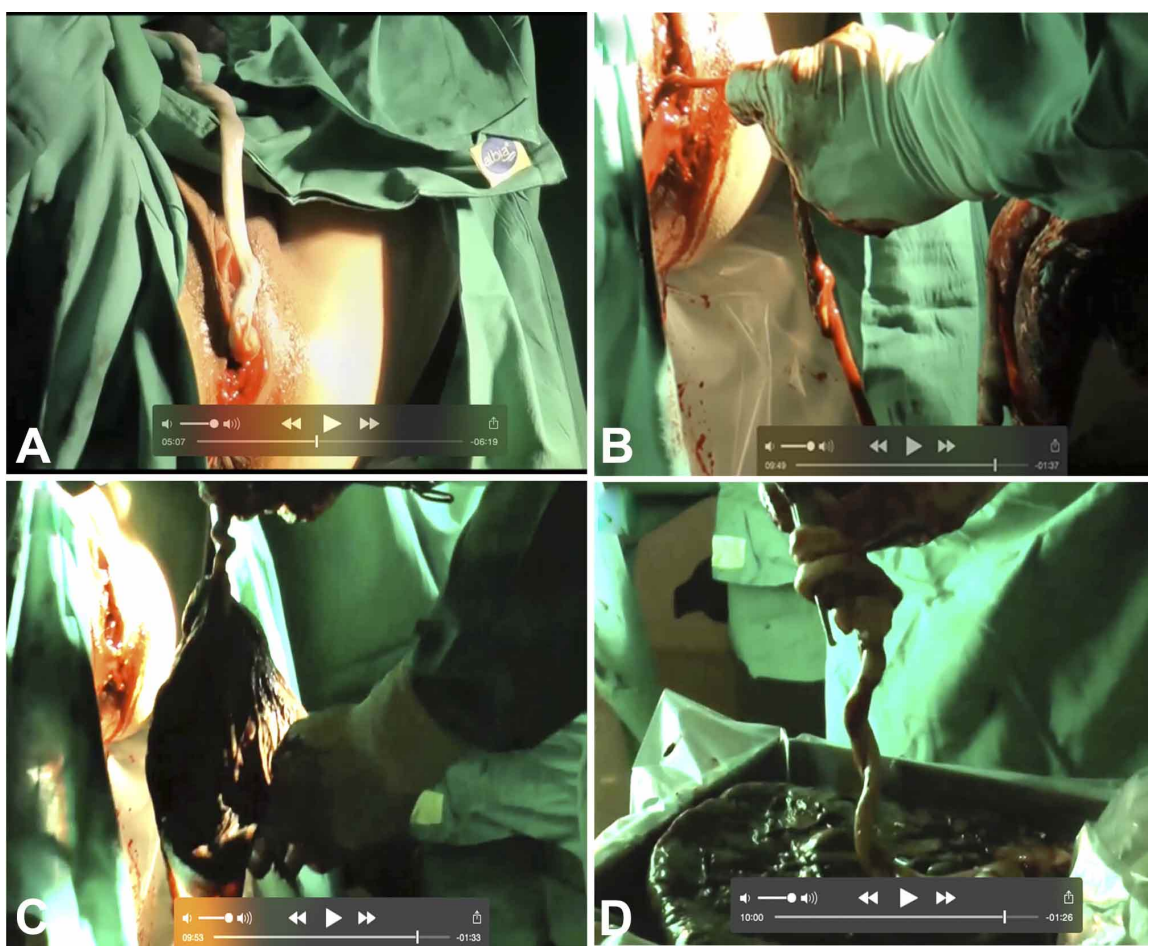

Fig. 3. Video ficticio de alumbramiento patológico. En la imagen A se observó el cordón umbilical protruyendo desde la vulva. En la imagen B la placenta ya fue expulsada, nótese que el profesional que atiende el parto trata de extraer los restos de membranas placentarias (amnios, corion liso). La imagen $\mathrm{C}$ y D corresponden a la etapa final del proceso de alumbramiento donde se advierte la cara fetal de la placenta y su forma discoidea. 
Tabla I. Cuestionario sobre percepción de los estudiantes de obstetricia de la lección MOODLE "placenta”.

\begin{tabular}{|c|c|c|c|c|c|c|}
\hline $\mathrm{N}^{\circ}$ & $\begin{array}{l}\text { Indicadores basados en lección MOODLE } \\
\text { "Placenta" }\end{array}$ & $\begin{array}{l}\text { Muy a } \\
\text { menudo }\end{array}$ & A menudo & $\begin{array}{l}\text { Algunas } \\
\text { veces }\end{array}$ & Rara vez & Casi nunca \\
\hline $1 .-$ & $\begin{array}{l}\text { Mi trabajo habitual en las clases teóricas está } \\
\text { integrado con la lección MOODLE. }\end{array}$ & & & & & \\
\hline 2.- & $\begin{array}{l}\text { La información de la lección MOODLE me ayudo } \\
\text { a obtener mejores resultados en mi aprendizaje. }\end{array}$ & & & & & \\
\hline 3.- & La lección MOODLE es de fácil acceso. & & & & & \\
\hline 4.- & $\begin{array}{l}\text { Para finalizar con éxito la lección MOODLE debo } \\
\text { cumplir ciertas reglas. }\end{array}$ & & & & & \\
\hline 5.- & $\begin{array}{l}\text { Utilizo los contenidos teóricos de mis clases en la } \\
\text { lección MOODLE. }\end{array}$ & & & & & \\
\hline 6.- & $\begin{array}{l}\text { La información de la lección MOODLE me ayudo } \\
\text { a obtener mejores calificaciones en la asignatura. }\end{array}$ & & & & & \\
\hline 7.- & Me agrada el formato de la lección MOODLE. & & & & & \\
\hline 8.- & $\begin{array}{l}\text { Los temas tratados en las clases teóricas son } \\
\text { similares a los tratados en la lección MOODLE. }\end{array}$ & & & & & \\
\hline 9.- & $\begin{array}{l}\text { La lección MOODLE me permite trabajar de } \\
\text { forma autónoma. }\end{array}$ & & & & & \\
\hline 10.- & $\begin{array}{l}\text { Las actividades y recursos de la lección MOODLE } \\
\text { funcionaron correctamente. }\end{array}$ & & & & & \\
\hline 11.- & $\begin{array}{l}\text { La lección MOODLE es un buen complemento } \\
\text { didáctico a las clases teóricas expositivas. }\end{array}$ & & & & & \\
\hline 12.- & $\begin{array}{l}\text { En la lección MOODLE existe una organización } \\
\text { clara y ordenada de la información. }\end{array}$ & & & & & \\
\hline 13.- & $\begin{array}{l}\text { Lo que hago en la lección MOODLE me ayuda a } \\
\text { entender las clases teóricas. }\end{array}$ & & & & & \\
\hline 14.- & $\begin{array}{l}\text { La lección MOODLE permite autoevaluar mi } \\
\text { desempeño. }\end{array}$ & & & & & \\
\hline 15.- & $\begin{array}{l}\text { Los recursos (actividades, videos, fotografías) de } \\
\text { la lección estuvieron bien diseñados. }\end{array}$ & & & & & \\
\hline 16.- & $\begin{array}{l}\text { La lección MOODLE posee objetivos claros que guíen } \\
\text { el proceso de enseñanza y aprendizaje. }\end{array}$ & & & & & \\
\hline
\end{tabular}

\section{RESULTADOS}

En relación a los indicadores pertenecientes a la dimensión aporte al proceso de enseñanza y aprendizaje un $52,94 \%$ de los estudiantes señalan que "muy a menudo" "Utilizo los contenidos teóricos de mis clases en la lección MOODLE" y un 29,41 \% que "a menudo". Por otro lado, un $60,29 \%$ de los estudiantes menciona que "muy a menudo" "Los temas tratados en las clases teóricas son similares a los tratados en la lección MOODLE". En esta línea, un $47,79 \%$ describe que "muy a menudo" "Lo que hago en la lección MOODLE me ayuda a entender las clases teóricas" y $34,56 \%$ que "a menudo".

En la dimensión integración entre la lección MOODLE y las clases expositivas un 70,59\% de los estudiantes menciona que "muy a menudo" "la lección MOODLE me permite trabajar de forma autónoma" y un 20,59 \% que "a menudo". En este contexto, un 63,97\% de los estudiantes señala que "la lección MOODLE es un buen complemento didáctico a las clases teóricas expositivas" y un 27,21 \% que "a menudo". Un $50 \%$ de los estudiantes indicó que "muy a menudo" "la lección MOODLE me ayudó a obtener mejores resultados en mi aprendizaje" y un 35,29 \% que "a menudo".

En la dimensión formato y estructura de la lección un $74,26 \%$ de los estudiantes señala que "muy a menudo" "la lección MOODLE es de fácil acceso" y un 22,06 \% que "a menudo". Por otro lado, un 55,88 \% de los estudiantes señalan que "muy a menudo" "los recursos (actividades, videos, fotografías) de la lección estuvieron bien diseñados" y un $34,56 \%$ que "a menudo". 
En la dimensión normas que orientan la conducta en las lecciones, un 63,97\% de los estudiantes señala que "muy a menudo" "la lección MOODLE posee objetivos claros que guían el proceso de enseñanza y aprendizaje" y un 30, $88 \%$ que "a menudo".

\section{DISCUSIÓN}

Existe una valoración positiva de los estudiantes de la lección MOODLE sobre anatomía e histología placentaria humana como complemento a las clases teóricas presenciales. Nuestros resultados están en concordancia con otras experiencias similares publicadas en la literatura en el campo de la Medicina, Obstetricia, Fisioterapia y Educación Secundaria, las cuales señalan efectos benéficos para el aprendizaje de los estudiantes de diferentes formas (Bucarey et al.; Prieto et al.; Selvakumaran et al., 2011; Granero-Gallegos \& BaenaExtremera; Subramanian \& Perumal; Popovic et al.).

En relación a la dimensión "integración" encontramos que el indicador "la lección MOODLE es un buen complemento didáctico a las clases teóricas expositivas", alcanzó un porcentaje de satisfacción de un 63,97\%, resultado que se encuentra en línea con el $65 \%$ obtenido por Popovic et al., para un indicador similar. Por otro lado, el indicador "la lección MOODLE me ayudó a obtener mejores resultados en mi aprendizaje" un $50 \%$ de los estudiantes señala que "muy a menudo" y un 35,29 \% que "a menudo". Los resultados antes expuestos concuerdan con la experiencia del equipo de Granero-Gallegos \& Baena-Extremera al comprobar que la utilización de MOODLE mejora los resultados académicos en estudiantes de secundaria en la asignatura de educación física.

En lo que respecta a la dimensión "aporte al proceso de enseñanza y aprendizaje", el indicador "lo que hago en la lección MOODLE me ayuda a entender las clases teóricas" un 47,79 \% describió que "muy a menudo" y un $34,56 \%$ que "a menudo". Dichos resultados coinciden con lo reportado por Subramanian \& Perumal donde un $72 \%$ de los estudiantes perciben que gracias a esta modalidad mixta les fue mucho más fácil la comprensión de los contenidos.

Por otra parte, en la dimensión "formato y estructura de la lección", en el indicador "lección MOODLE es de fácil acceso" un 74,26\% de los estudiantes señalan que "muy a menudo". Los resultados antes expuestos están en línea con lo reportado por Popovic et al., quienes señalaron que en un $90 \%$ de los estudiantes de Medicina mencionaron que la plataforma MOODLE fue de fácil uso en el contexto del curso de Fisiología”. En relación, al indicador "los recursos (actividades, videos, fotografías) de la lección estuvieron bien diseñados" un 55,88 \% de los estudiantes señalan que "muy a menudo" y un 34,56 \% que "a menudo". Prieto et al. desarrolló un blog de placenta comparada donde en un $62 \%$ de los estudiantes les pareció atractivo, ordenado, didáctico y un 59,2 \% valoró los aspectos microscópicos como de fácil compresión y novedosos. Ambas experiencias coinciden en una valoración positiva del diseño y contenido audiovisual utilizado en sus iniciativas en herramientas didácticas montadas.

En la dimensión "normas que guían la conducta en las lecciones" un 63,97 \% de los estudiantes señaló que "muy a menudo" "la lección MOODLE posee objetivos claros que guían el proceso de enseñanza y aprendizaje" y un 30,88 \% que "a menudo". Resultados similares reportó Bucarey et al., ya que un $67 \%$ de los estudiantes señaló que los objetivos de la lección LAMS eran comprensibles.

La valoración positiva de la lección de parte de los estudiantes nos impulsa a desarrollar nuevas lecciones complementarias a las clases expositivas en otras unidades temáticas de difícil comprensión, obtención y conservación de material biológico: sistema nervioso y renal, embriología humana, entre otros. No obstante, como lo han señalado otros autores creemos que este tipo de iniciativas no reemplaza el rol del profesor en la formación integral de profesionales de la salud (Cabral \& Barbosa, 2005; Prieto et al.).

\section{AGRADECIMIENTOS}

Proyecto innovación docente $\mathrm{N}^{\circ} 005-2016$, Vicerrectoría Académica Universidad de Santiago de Chile, Usach. Los autores agradecen al Servicio de Ginecología y Obstetricia del Hospital San José (Chile) por colaborar con la grabación del video de alumbramiento. También, nuestro reconocimiento al Dr. Sebastián San Martín académico de la Universidad de Valparaíso (Chile) por proporcionar las muestras histológicas de placenta humana.

GODOY-GUZMÁN, C; OSSES, M; SAN MARTÍN, S; LEIVA, G. \& JARA-ROSALES, S. MOODLE lesson of the anatomy and histology of the human placenta. Int. J. Morphol., 37(1):178-183, 2019.

SUMMARY: The lack of existing human biological samples, mainly due to the ethical-moral restrictions related to obtaining these, highlights the need to search for other teaching and learning alternatives in morphological science. In this sense, 
the implementation of lessons by means of the MOODLE platform provides the students with the opportunity to interact in a setting that simulates a learning situation that belongs to traditional laboratories. The purpose of this work was to generate a MOODLE lesson on the anatomy and histology of the human placenta, as a complement of the traditional theoretical classroom for students of Obstetrics. To that end, TIC information, images, and resources were sought in libraries and in the Internet, and at the same time a set of histological photographs of placenta samples was made, as well as a video recording of a placental delivery. Later, the coordination and set up of activities was made in the MOODLE platform with a constructivist approach. Furthermore, a satisfaction survey was prepared which was validated by three experts. The total sample consisted of 137 students in the 2 th year of obstetrics. A virtual MOODLE laboratory of the anatomy and histology of the human placenta was made, which is constituted by multiple activities with a clinical orientation that allow self-evaluation. The virtual laboratory has helped overcome the lack of human samples, and results of the satisfaction survey applied to the students indicate a positive evaluation of this initiative.

KEY WORDS: MOODLE; Human placenta; Histology; Anatomy.

\section{REFERENCIAS BIBLIOGRÁFICAS}

Blanco, E. A. El uso y el conocimiento de los contenidos de educación física en Internet del alumnado de segundo ciclo de Educación Secundaria Obligatoria. Estudio de caso. Enseñ. Teach., 31(2):69-92, 2013.

Bucarey, A. S.; Araya, A. E.; Cabezas, O. X. \& Álvarez, G. L. Anatomy contents in learning designs displayed in LAMS and integrated to Moodle. Int. J. Morphol., 29(2):363-70, 2011.

Cabral, D. E. \& Barbosa, N. J. M. Students' opinions on the use of computer rooms for teaching Anatomy. Int. J. Morphol., 23(3):261-70, 2005.

Chaparro Gómez, L. E. Uso de los casos clínicos como estrategia didáctica en la enseñanza de anestesia. Rev. Colomb. Anestesiol., 32(4):281-4, 2004.

Dougiamas, M. \& Taylor, P. Interpretive analysis of an internet-based course constructed using a new courseware tool called Moodle. Perth, Proceedings of the Higher Education Research and Development Society of Australasia (HERDSA) Conference, 2002.

Dougiamas, M. \& Taylor, P. Moodle: using learning communities to create an open source course management system. Honolulu, EdMedia-2003 Conference, 2003.

Fraser, B.; Giddings, G. \& McRobbie, C. J. Evolution and validation of a personal form of an instrument for assessing science laboratory classroom environments. J. Res. Sci. Teach., 32(4):399-422, 1995.

Godoy-Guzmán, C.; San Martin, S. \& Pereda, J. Proteoglycan and collagen expression during human air conducting system development. Eur. J. Histochem., 56(3):e29, 2012.

Granero-Gallegos, A. \& Baena-Extremera, A. Patterns of ICT-based Learning (Moodle and Mahara 2.0) for contents of anatomy, physiology and health in scholar physical education lessons. Int. J. Morphol., 33(1):375-81, 2015.

Merino Malillos, L. Nativos Digitales: Una Aproximación a la Socialización Tecnológica de los Jóvenes. Tesis. Lejona, Universidad del País Vasco, 2010.

Popovic, N.; Popovic, T.; Rovcanin Dragovic, I. \& Cmiljanic, O. A Moodle-based blended learning solution for physiology education in Montenegro: a case study. Adv. Physiol. Educ., 42(1):111-7, 2018.
Prieto, R.; Smok, C. \& Rojas, M. Blog experiences: compared placenta Int. J. Morphol., 29(2):432-5, 2011.

Roselli, D. A. La Presentación de un Caso: Las Series de Casos. En: Ruiz Morales, A. (Ed.). Epidemiología Clínica: Investigación Clínica Aplicada. Bogotá, Centro Editorial Javeriano, Facultad de Medicina, Pontificia Universidad Javeriana, 2001. pp.237-43.

Selvakumaran, K.; Jusof, F. F.; Ismail, R. \& Husain, R. Integrating an open-source course management system (Moodle) into the teaching of a first-year medical physiology course: a case study. Adv. Physiol. Educ., 35(4):369-77, 2011.

Subramanian, G. S. \& Perumal, V. Moodle based e-learning resource for revising clinical anatomy: an inexpensive and interactive supplement for physiotherapy students. Int. J. Physiother., 3(4):409-14, 2016.

\author{
Dirección para correspondencia: \\ Prof. Asoc. Dr. Carlos Godoy-Guzmán \\ Escuela de Medicina \\ Facultad de Ciencias Médicas \\ Universidad de Santiago de Chile \\ Avda. Bdo. O'Higgins 3363 \\ Santiago \\ CHILE
}

Email: carlos.godoy@usach.cl

Recibido : 29-06-2018

Aceptado: 12-11-2018 